\title{
PERSPECTIVES DEMOGRÁFIQUES
}

\section{Joint Custody: One More Step towards Gender Equality?}

\section{Montse Solsona and Marc Ajenjo, Centre d'Estudis Demogràfics and Universitat Autònoma de Barcelona}

Data published by the National Statistics Institute (INE in the Spanish acronym) show that, since 2011, the figures for divorces are remarkably stable at around 100,000 every year with half of them involving offspring who are still minors. However, there has been a notable spike in shared custody to the detriment of the earlier paradigm of the mother having exclusive custody and the father visitation rights. Between 2011 and 2016 the figure for joint custody rose from 12\% to $28 \%$ of divorces where minors are involved. This increase, led by the autonomous regions of Spain with favourable legislation, reflects social changes of a broader scope embracing gender equality within and outside the home.

Analysis of the INE series, in addition to work on all 5,894 never-previously-explored divorce and separation (for de facto couples) settlements from the family courts of the city of Barcelona, shows that shared custody means, at least on paper, equity between father and mother, both with regard to alternating residence of the children and also sharing child-related costs.

Given this situation, one might ask whether it might be a good idea to grant joint custody by default after the parents have separated. The answer is a resounding no. Joint custody should be the result of an agreement that reflects prior co-parenting practice in equality, and this is far from being a majority situation nowadays.

\section{THE TWO SPAINS}

The increase in joint custody between 2011 and 2016 has occurred solely to the detriment of exclusive custody of the mother since exclusive custody granted to the father remains constant at about $5 \%$. Although joint custody has increased in all the autonomous regions, the very uneven pace has accentuated differences (see Figure 1). The regions with the highest percentages of joint custody, and clearly above the average for Spain, are the Balearic Islands, Catalonia, Valencia, Aragon, the Basque Country, Navarre and La Rioja. In only five years-2011 to 2016-they have all shown rises of up to 20 percentage points in the prevalence of joint custody. As the two maps of Figure 2 demonstrate, the regions with the highest incidence of joint custody, with the exception of the Balearic Islands and La Rioja, coincide with those which have their own legislation in favour of co-parenting after divorce. In a recent study we show that besides the importance of the legislation, the most important explanatory factor with regard to joint custody is the existence of more egalitarian gender relations in the couple and in society in general and, in particular, in distribution of productive and care work (Solsona, Spijker and Ajenjo, 2017).

FIGURE 1. Evolution of joint custody by autonomous region, 2011-2016 (in \% of total of custody arrangements)

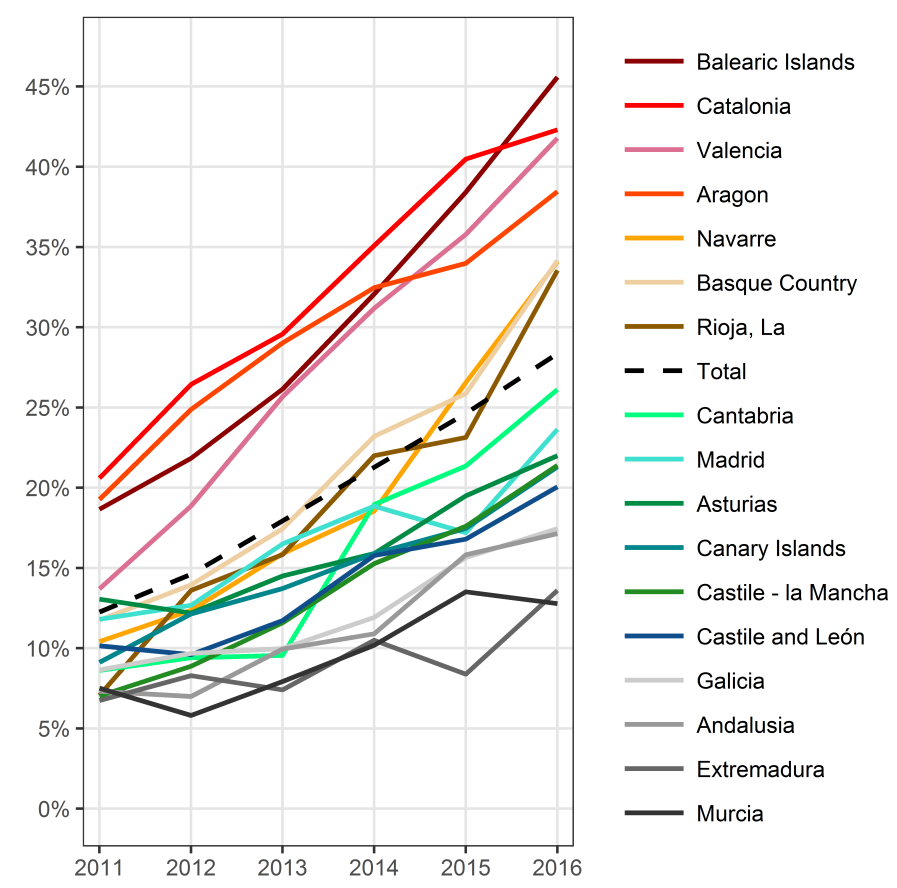

Source: Compiled by authors on the basis of divorce statistics microdata made available by the INE 


\section{IMPLICATIONS FOR DEMOGRAPHY}

Joint custody has direct implications for demography. It should be borne in mind that a little over half of the couples which divorced between 2011 and 2016 had children-a total of 480,000 under the age of 18 -for whom decisions had to be made as to their custody. Parents were granted joint custody in the cases of 100,000 of these minors. Although these data do not show exactly how many under-

FIGURE 2. Law of the autonomous regions and joint custody by region, 2016 (in \% of total of custody arrangements)

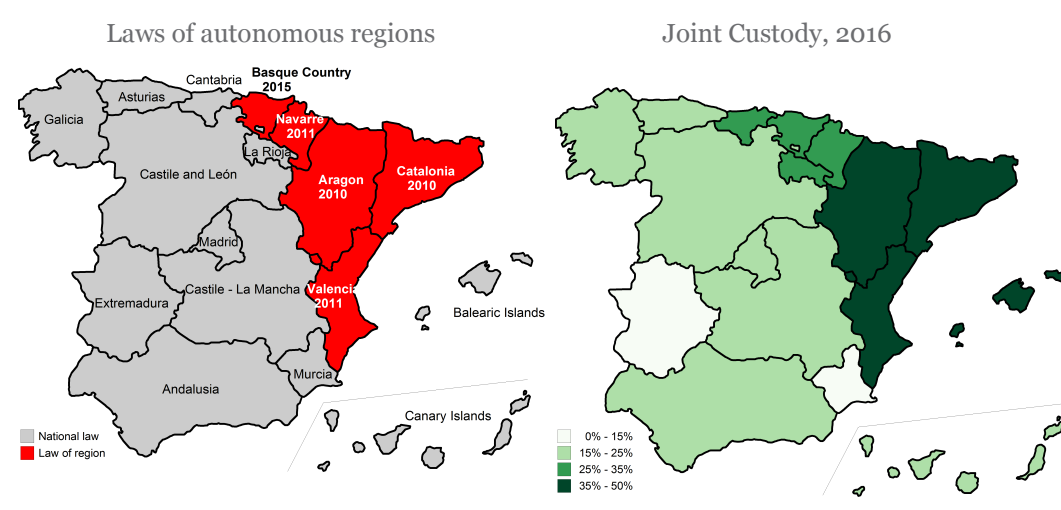

Source: Compiled by authors on the basis of divorce statistics microdata made available by the INE.

18s presently live in a system of alternating residence, the survey Health Behaviour in School-Aged Children (Moreno et al. 2016) shows that, in 2014, approximately 5\% of children aged between 11 and 16 were subject to the joint custody system. A simple calculation suggests that, in Spain, almost 150,000 adolescents were dividing their lives between two homes in 2014. Hence, by contrast with information provided by the population census in which, by legal requirement, each person is allocated a single residence, a not inconsiderable part of the population actually has dual residency.

Moreover, the official statistics of the INE on separation and divorce do not include breakups of de facto couples although, as shown below, this group is increasingly numerous and with quite distinctive characteristics. Statistics including these are necessary.

\section{WHAT DO WE MEAN WHEN WE SPEAK OF JOINT CUSTODY?}

This may be illustrated in a case study for the city of Barcelona in which joint custody is analysed as a legal fact on the basis of the 5,894 rulings made in the family courts in 2014. Directly scrutinising these rulings, we have been able to include for the first time, besides the court proceedings for marriage breakups, those for the separation of de facto couples with children, since both cases are subject to the same legal procedure. Hence, we have been able to ascertain that, of the total of cases where custody of children was settled, $37 \%$ are accounted for by de facto couples.

The main results of our research allow us to refute two myths. The first refers to banalisation of joint custody in the form of a hypothesis raised on several occasions by legal practitioners in 2014. Their impression was that, in Barcelona, if the stipulations of the Catalan Law of 2010-experience of joint care before the breakup, ability of each parent to undertake parental duties, and the willingness of both parents to cooperate constantly, among othersare taken into account, an excessive number of joint custody arrangements was being granted. The results of our research, however, do not point to this conclusion, inasmuch as the figures for childcare co-responsibility of fathers and mothers are higher than those for the cases of joint custody granted. The fact is, in Barcelona

in 2014, couples which were granted joint custody on separation-25.3\%-were not as numerous as the couples which, with children aged under 18 , shared housework and childcare in conditions of equality. According to the time-use survey of 2009-2010, the figure in this case was $30.8 \%$. Although a cause-effect result cannot be deduced from this, the figures would suggest that, in the case of Barcelona and, by extension, Catalonia, the criterion of co-parenting prior to the divorce would seem to be well-founded.

The second myth refers to the situation of de facto couples. Everything appears to indicate that people who live together without going through the legal formalities, and who are in principle more accustomed to pacts, would resolve their breakup without the intervention of a judge and would show higher levels of joint custody. For de facto couples who go through the courts, at least, this is not the case. They show higher levels of conflict (so that, in legal terms, the case is decided in contentious proceedings where the judge has the last word) than married couples and, moreover, as Figure 3 shows, they present fewer cases of joint custody.

\section{AGREEMENT BETWEEN PARTNERS IS CRUCIAL}

Apart from the type of union concerned, Figure 3 shows other factors favouring the emerging paradigm of joint custody. Among the more relevant of these is unquestionably agreement between parents or, in legal terms, a procedure of mutual agreement. Joint custody is three times more likely when the couple agrees over the terms of separation than when the judge ends up deciding them.

The couple's place of origin also has significant explanatory power. 
When both parents are Spanish, the tendency to joint custody is four times greater than when both are from another country. However, it must also be stressed that the father's place of birth is more important than the mother's, with the result that joint custody is granted (or agreed) more when the father is Spanish and the mother from another country than in the reverse situation.

These results for Barcelona tally with research into the determining factors of joint custody-on the basis of INE statistics-carried out for Catalonia as a whole and the rest of Spain (Solsona and Spijker, 2016). In the study for Barcelona we have been able to go further and analyse the effects of other variables (like type of union, as we have seen, age of children and social class) which are not included in the INE statistics.

FIGURE 3. Joint custody in accordance with different variables. City of Barcelona, 2014 (in \% of total of custody arrangements)

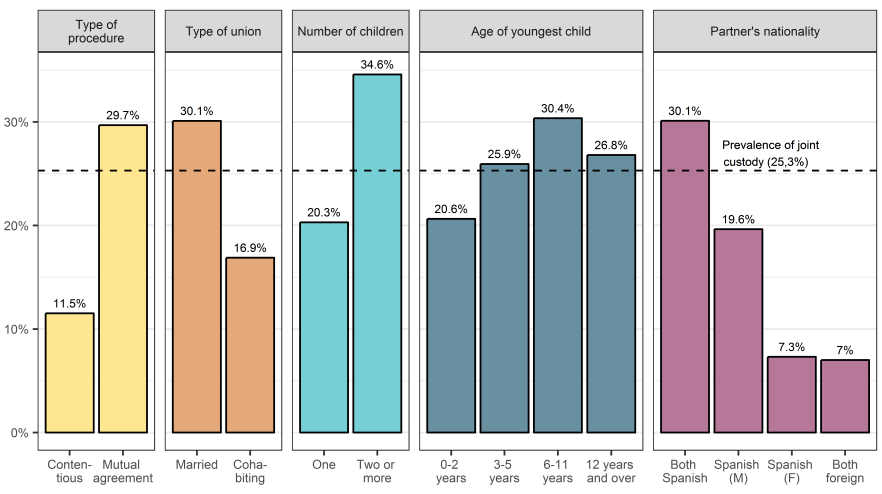

Source: Compiled by authors on the basis of all the family court decisions for the city of Barcelona

Joint custody is more frequent when the youngest child is aged between six and eleven, a result that is very much in tune with the opinion of a range of legal practitioners specialising in children who do not favour the movement of children of under six between two homes. After twelve, the figures for shared residency tend to fall.

Although it is only in the mutual agreement court proceedings -which is why this is not included in Figure 3-we have been able to show the effect of social class for Barcelona or, in other words, a clear positive relationship between family income and joint custody. Higher-income couples come to agreement over joint custody in $42 \%$ of the cases while for lower-income families the figure is only $24 \%$ and, for middle-class families, $32 \%$. This finding makes it possible to state that lack of resources has a negative effect, not only with regard to predisposition for divorce but also the possibility of having two homes in similar conditions.

Of all the factors involved, agreement is of crucial importance because it is part of managing the process of the breakup which per se entails some degree of conflict. Agreement is a principle enshrined in the Catalan Law of 2010 which offers an instrument, namely a Parenthood Plan which is designed to foster agreement between the two parties concerned (Solsona, Brullet and Spijker, 2014). Among other things, it also considers the rules for the children's stays in the homes of both parents. Indeed, agreement is essential, not only for co-parenthood but also for the children's academic results and well-being. In a recent study, Escarpa (2017) demonstrates that children of divorced parents who are not in conflict obtain better results at school than those who live in a two-parent household. Then again, in the Barcelona study we have analysed how distribution of childcare time and the financing of child-related costs, two elements which are essential for guaranteeing the well-being of children, are worked out between the mother and father.

\section{TIME AND MONEY IN GENDER EQUITY}

On paper, at least, joint custody suggests equity between the father and mother with regard to both time spent on childcare and childrelated expenditure.

Figure 4 shows the percentage of nights which, according to the court decision, under-18s spend in the father's house. If the agreement is the result of a pact or mutual agreement proceedings, equality in childcare time is absolute. The children sleep half their nights in the home of one parent and half in that of the other. Although to a lesser extent, this equality can also be seen in joint custody arising from contentious proceedings. The biggest difference between mutual agreement and contentious proceedings, which is accentuated still further when the mother has exclusive custody, appears

FIGURE 4. Alternating residency of children on school days and holidays* in accordance with type of custody and proceedings (mutual agreement or contentious). City of Barcelona, 2014 (\% of nights spent with father per year)

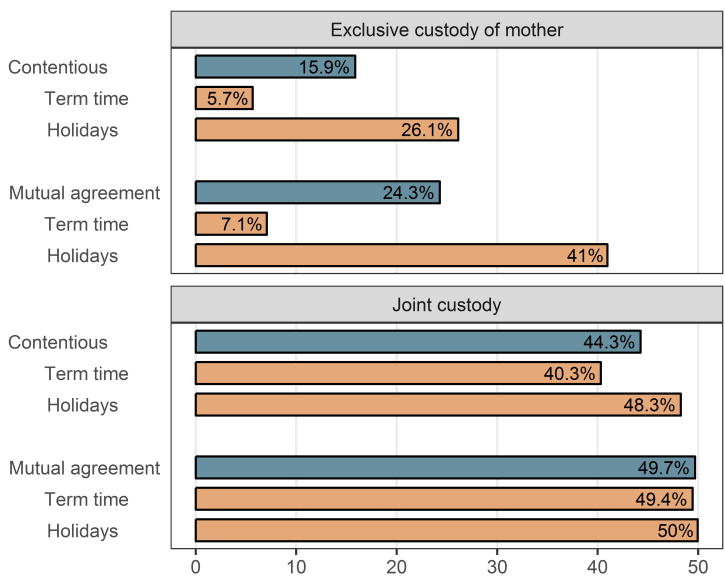

${ }^{*}$ Holidays include weekends, Christmas holidays, Holy Week and summer holidays. Source: Compiled by authors on the basis of rulings in all family courts of the city of Barcelona. 
withdivergence with regard to holidays (weekends and school holidays in general) and nights during term time. This difference is of prime importance since school days are also working days, which makes reconciliation between the productive and reproductive spheres more difficult.

This logic also appears in maintenance payments (Figure 5). In $88 \%$ of joint custody cases arising from mutual agreement neither of the parents pays-meaning that each one pays child-related expenses when it is their turn to have the child or children-or they both pay. In this latter case, men pay slightly more, probably because of their greater acquisitive power. When joint custody is the result of contentious proceedings, the father pays for child-related expenses in $50 \%$ of the cases. This type of arrangement is then situated at a point halfway between joint custody by mutual agreement and exclusive custody of the mother.

FIGURE 5. Maintenance of children in accordance with type of custody and procedure. City of Barcelona, 2014 (in \% of person paying).

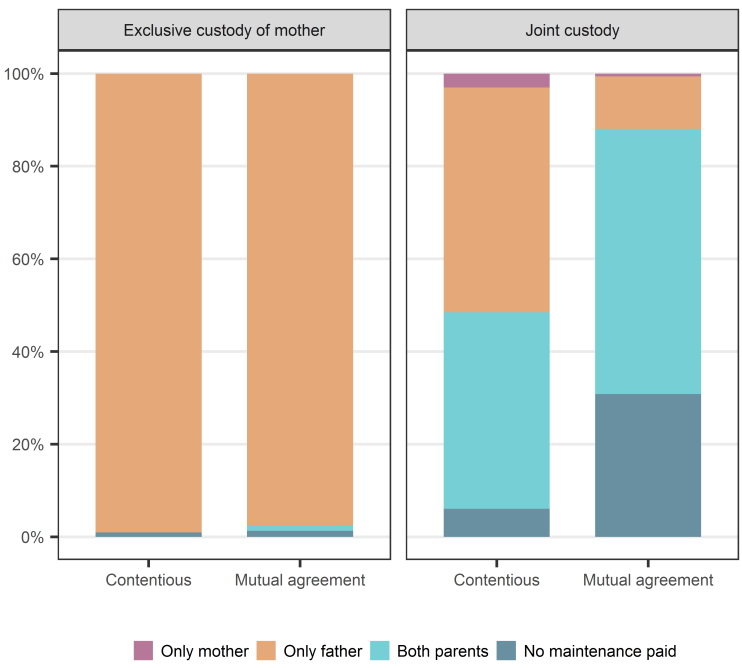

Source: Compiled by authors on the basis of rulings in all the family courts in the city of Barcelona

\section{Bibliography}

Ajenjo, M and García-Román, J (2014) "Cambios en el uso del tiempo de las parejas ¿Estamos en el camino hacia una mayor igualdad?", Revista Internacional de Sociología, 72 (2): 453-476 Escarpa, S (2017) "Effects of Post-Divorce Parental Conflict on Children's Educational Achievement", REIS, 158: 41-58.

Moreno, C; Ramos, P; Rivera, F et al. (2016) Informe técnico de los resultados obtenidos por el Estudio Health Behaviour in School-aged Children (HBSC) 2014 en España. Madrid: Ministerio de Sanidad, Servicios Sociales e Igualdad.

Solsona, M; Brullet, C and Spijker, J (2014) "Coparentalitat i custòdia comè partida a Catalunya", Documents d'Anàlisi Geogràfica, 60 (2): 387-415.
Solsona, M and Spijker, J (2016) "Does the 2010 Catalan Civil CodeAffect Trends in Joint Physical Custody? A Comparison between Catalonia and the Rest of Spain”, Population, 71 (2): 297-324.

Solsona, M; Spijker, J and Ajenjo, M (2017) "Calidoscopio de la custodia compartida en España" in Becerril, D and Venegas, M (eds.) La custodia comm partida en España. Madrid: Dykinson, 45-72.

\section{Citation}

Solsona, Montse and Ajenjo, Marc (2017) "Joint Custody: One More Step towards Gender Equality?”, Perspectives Demogràfiques, 8: 1-4.

Editors

Andreu Domingo and Albert Esteve

Then again, both Figure 4 and Figure 5 show that exclusive custody of the mother embraces the earlier paradigm in which inequalities in the exercise of motherhood and fatherhood flow together in three dimensions: time spent on childcare, a balance between work and family, and child-related expenses.

\section{JOINT CUSTODY REPRESENTS PROGRESS TOWARDS GENDER EQUALITY, BUT..}

We have studied the legal agreements to this point. The fit between the agreements and parental practice will depend, at the individual level, on the practice of co-responsibility before separation and, at the social level, on the solidity of social change concerning new parenthood. As we see it, sustainability over time of agreements and practices of co-parenthood in equity will accustom the younger generations of boys and girls to interchangeable childcare roles between their parents, which will work in favour of the acquisition of values of equity through their experience of socialisation.

Joint custody should be seen as an advance if it represents a reflection, as the Catalan law states, of co-responsibility prior to a couple's separation. An adequate legal response should not entail imposing joint custody but should take into account the childcare conditions before the breakup of the parents, and also allow the presently ever-increasing number of egalitarian parents (Ajenjo and García-Román, 2014) to pave the way, in cases of divorce, to a rise in the figures for joint custody.

However, if joint custody is awarded indiscriminately, the conflict between parents could worsen and, perhaps, the inequalities between them as well. Hence, application of a law that does not take into account the particularities of each and every case and its background, and that overlooks the fact that measures should not be imposed in a context where inequalities between men and women still persist, could clearly be counterproductive.

Please address correspondence to:

Montse Solsona

msolsona@ced.uab.cat

Credits

Research design: Montse Solsona, Cristina Brullet and Marc Ajenjo

Fieldwork and database: Amalia Gómez Casillas

Graphics: Anna Turu

Layout

Xavier Ruiz Vilchez

Acknowledgements

Our thanks to Montserrat Tur, to the staff of the Family Courts, Barcelona Law Courts and to all the fieldwork team.

\section{URL}

http://ced.uab.es/difusio/butlleti-perspectives-demografiques/

Contact

Centre d'Estudis Demogràfics. Carrer de Ca n'Altayó, Edifici E2 Universitat Autònoma de Barcelona o8193 Bellaterra / Barcelona Spain

Telephone: +34 935813060 Email:demog@ced.uab.cat Web page: www.ced.uab.cat

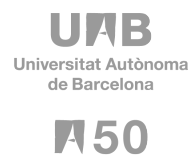

